\title{
OPTIMALLY STAGGERED FINNED CIRCULAR AND ELLIPTIC TUBES IN FORCED CONVECTION
}

\begin{abstract}
R. S. Matos ${ }^{\mathrm{a}}$,
T. A. Laursen ${ }^{b}$,

J. V. C. Vargas ${ }^{\mathrm{a}}$, and A. Bejanc,

${ }^{\text {a}}$ Universidade Federal do Paraná

Departamento de Engenharia Mecânica

Centro Politécnico

Bairro Jardim das Américas

CP:19011, Curitiba, Paraná, Brasil

rudmar@demec.ufpr.br

${ }^{b}$ Duke University

Department of Civil and Environmental

Engineering

Durham, NC, 27708-0287, USA

${ }^{c}$ Duke University

Department of of Mechanical Engineering \&

Materials Science

Durham, NC, 27708-0300, USA

ABSTRACT
This work presents a three-dimensional (3-D) numerical and experimental geometric

optimization study to maximize the total heat transfer rate between a bundle of finned tubes in a given volume and a given external flow both for circular and elliptic arrangements, for general staggered configurations. The optimization procedure started by recognizing the design limited space availability as a fixed volume constraint. The experimental results were obtained for circular and elliptic configurations with a fixed number of tubes (12), starting with an equilateral triangle configuration, which fitted uniformly into the fixed volume with a resulting maximum dimensionless tube-to-tube spacing $S / 2 b=1.5$, where $S$ is the actual spacing and $b$ is the smaller ellipse semi-axis. Several experimental configurations were built by reducing the tube-to-tube spacings, identifying the optimal spacing for maximum heat transfer. Similarly, it was possible to investigate the existence of optima with respect to other two geometric degrees of freedom, i.e., tube eccentricity and fin-to-fin spacing. The results are reported for air as the external fluid in the laminar regime, for $\operatorname{Re}_{2 b}=100$ and 125 , where $2 \mathrm{~b}$ is the ellipses smaller axis length. Circular and elliptic arrangements with the same flow obstruction cross-sectional area were compared on the basis of maximum total heat transfer. This criterion allows one to quantify the heat transfer gain in the most isolated way possible, by studying arrangements with equivalent total pressure drops independently of the tube cross section shape. This paper reports three-dimensional (3D) numerical optimization results for finned circular and elliptic tubes arrangements, which are validated by direct comparison with experimental measurements with good agreement. Global optima with respect to tube-to-tube spacing, eccentricity and fin-to-

fin spacing $\left(\mathrm{S} / 2 \mathrm{~b} \cong 0.5, \mathrm{e} \cong 0.5\right.$ and $\phi_{\mathrm{f}} \cong 0.06$ for $\operatorname{Re}_{2 \mathrm{~b}}=100$ and 125 , respectively) were found and reported in general dimensionless variables. A relative heat transfer gain of up to $19 \%$ is observed in the optimal elliptic arrangement, as compared to the optimal circular one. The heat transfer gain, combined with the relative material mass reduction of up to $32 \%$ observed in the optimal elliptic arrangement in comparison to the circular one, show the elliptical arrangement has the potential for a considerably better overall performance and lower cost than the traditional circular geometry.
\end{abstract}

\section{INTRODUCTION}

The optimization of industrial processes for maximum utilization of the available energy (exergy) has been a very active line of scientific research in recent times. The increase in energy demand in all sectors of the human society requires an increasingly more intelligent use of available energy. Many industrial applications require the use of heat exchangers with tubes arrangements, either finned or non-finned, functioning as heat exchangers in air conditioning systems, refrigeration, heaters, radiators, etc. Such devices have to be designed according to the availability of space in the device containing them. A measure of the evolution of such equipment, therefore, is the reduction in size, or in ocuppied volume, accompanied by the maintenance or improvement of its performance. Hence, the problem consists of identifying a configuration that provides maximum heat transfer for a given space (Bejan, 2000).

The main focus of this work is on the experimental and numerical geometric optimization of staggered finned circular and elliptic tubes in a fixed volume to obtain global optima with respect to tube-to-tube spacing, eccentricity and fin-to-fin spacing. In this work, a three-dimensional (3-D) numerical optimization procedure

for finned circular and elliptic arrangements is conducted and validated by means of direct comparison to experimental measurements to search the optimal geometric parameters in general staggered finned circular and elliptic configurations for maximum heat transfer. Circular and elliptic arrangements with the same flow obstruction cross-sectional area are then compared on the basis of maximum total heat transfer. Appropriate nondimensional groups are defined and the optimization results reported in dimensionless charts.

\section{THEORY}

A typical four-row tube and plate fin heat exchanger with a general staggered configuration is shown in Fig. 1. Fowler and Bejan, (1994) showed that in the laminar regime, the flow through a large bank of cylinders can be simulated 


\section{CIÊNCIA/SCIENCE}

accurately by calculating the flow through a single channel, such as that illustrated by the unit cell seen in Fig. 1. Because of the geometric symmetries, there is no fluid exchange or heat transfer between adjacent channels, or at the top and side surfaces. At the bottom of each unit cell, no heat transfer is expected across the plate fin midplane. In Fig. 1, L, H and W are the length, height and width (tube length) of the array, respectively. The fins are identical, where $t_{f}$ is the thickness and $\delta$, is the fin-to-fin spacing.

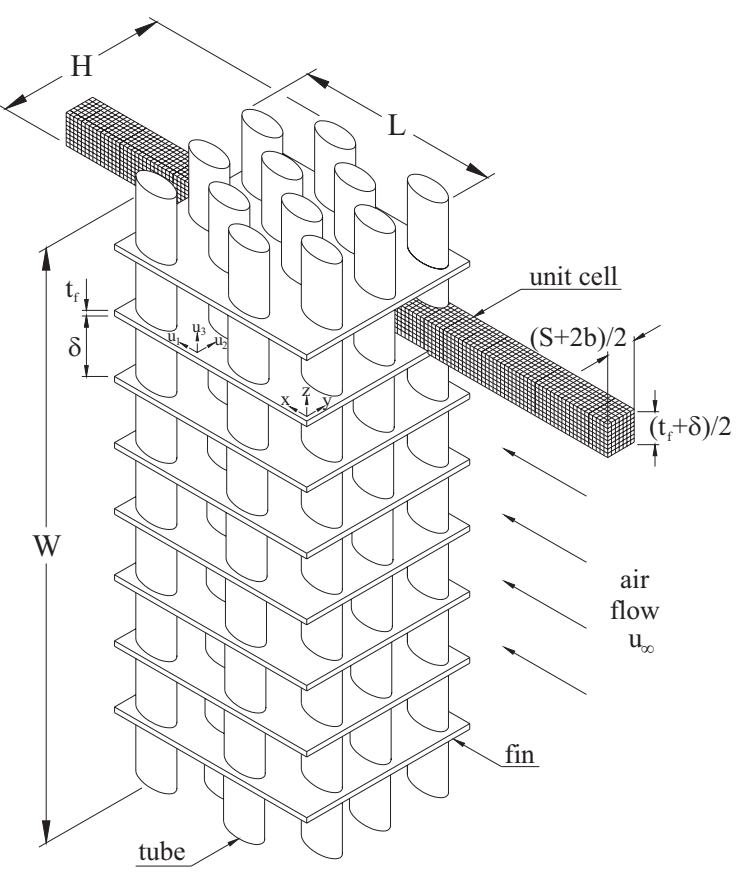

Figure 1. Arrangement of finned elliptic tubes, and the three dimensional computational domain.

The governing equations are the mass, momentum and energy equations which were simplified in accordance with the assumptions of three-dimensional incompressible steady-state laminar flow with constant properties, for a Newtonian fluid (Bejan, 1995):

$$
\begin{aligned}
& \frac{\partial \mathrm{U}_{1}}{\partial \mathrm{X}}+\frac{\partial \mathrm{U}_{2}}{\partial \mathrm{Y}}+\frac{\partial \mathrm{U}_{3}}{\partial \mathrm{Z}}=0 \\
& \mathrm{U}_{1} \frac{\partial \mathrm{U}_{1}}{\partial \mathrm{X}}+\mathrm{U}_{2} \frac{\partial \mathrm{U}_{1}}{\partial \mathrm{Y}}+\mathrm{U}_{3} \frac{\partial \mathrm{U}_{1}}{\partial \mathrm{Z}} \\
& =-\frac{\partial \mathrm{P}}{\partial \mathrm{X}}+\frac{1}{\mathrm{Re}_{2 \mathrm{~b}}} \frac{2 \mathrm{~b}}{\mathrm{~L}}\left[\frac{\partial^{2} \mathrm{U}_{1}}{\partial \mathrm{X}^{2}}+\frac{\partial^{2} \mathrm{U}_{1}}{\partial \mathrm{Y}^{2}}+\frac{\partial^{2} \mathrm{U}_{1}}{\partial \mathrm{Z}^{2}}\right] \\
& \mathrm{U}_{1} \frac{\partial \mathrm{U}_{2}}{\partial \mathrm{X}}+\mathrm{U}_{2} \frac{\partial \mathrm{U}_{2}}{\partial \mathrm{Y}}+\mathrm{U}_{3} \frac{\partial \mathrm{U}_{2}}{\partial \mathrm{Z}} \\
& =-\frac{\partial \mathrm{P}}{\partial \mathrm{Y}}+\frac{1}{\mathrm{Re}_{2 \mathrm{~b}}} \frac{2 \mathrm{~b}}{\mathrm{~L}}\left[\frac{\partial^{2} \mathrm{U}_{2}}{\partial \mathrm{X}^{2}}+\frac{\partial^{2} \mathrm{U}_{2}}{\partial \mathrm{Y}^{2}}+\frac{\partial^{2} \mathrm{U}_{2}}{\partial \mathrm{Z}^{2}}\right] \\
& \mathrm{U}_{1} \frac{\partial \mathrm{U}_{3}}{\partial \mathrm{X}}+\mathrm{U}_{2} \frac{\partial \mathrm{U}_{3}}{\partial \mathrm{Y}}+\mathrm{U}_{3} \frac{\partial \mathrm{U}_{3}}{\partial \mathrm{Z}} \\
& =-\frac{\partial \mathrm{P}}{\partial \mathrm{Z}}+\frac{1}{\mathrm{Re}_{2 \mathrm{~b}}} \frac{2 \mathrm{~b}}{\mathrm{~L}}\left[\frac{\partial^{2} \mathrm{U}_{3}}{\partial \mathrm{X}^{2}}+\frac{\partial^{2} \mathrm{U}_{3}}{\partial \mathrm{Y}^{2}}+\frac{\partial^{2} \mathrm{U}_{3}}{\partial \mathrm{Z}^{2}}\right] \\
& \mathrm{U}_{1} \frac{\partial \theta}{\partial \mathrm{X}}+\mathrm{U}_{2} \frac{\partial \theta}{\partial \mathrm{Y}}+\mathrm{U}_{3} \frac{\partial \theta}{\partial \mathrm{Z}}
\end{aligned}
$$

$$
=\frac{1}{\mathrm{Pe}_{2 b}} \frac{2 b}{L}\left[\frac{\partial^{2} \theta}{\partial X^{2}}+\frac{\partial^{2} \theta}{\partial Y^{2}}+\frac{\partial^{2} \theta}{\partial Z^{2}}\right]
$$

The symmetries present in the problem allow the solution (computational) domain to be reduced, to one unit cell, represented by the extended domain shown in Fig. 1, of height $(\mathrm{S} / 2+\mathrm{b})$, and width $\left(\delta / 2+\mathrm{t}_{\mathrm{f}} / 2\right)$.

In Eqs. (1) - (5), dimensionless variables have been defined based on appropriate physical scales as follows:

$$
\begin{aligned}
& (X, Y, Z)=\frac{(x, y, z)}{L} ; P=\frac{p}{\rho u_{\infty}^{2}} \\
& \left(U_{1}, U_{2}, U_{3}\right)=\frac{\left(u_{1}, u_{2}, u_{3}\right)}{u_{\infty}} ; \theta=\frac{T-T_{\text {in }}}{T_{w}-T_{\text {in }}} ; \\
& \operatorname{Re}_{2 b}=\frac{U_{\infty} 2 b}{v} \text { and } P_{2 b}=\frac{U_{\infty} 2 b}{\alpha}
\end{aligned}
$$

where $(\mathrm{x}, \mathrm{y}, \mathrm{z})$ are the Cartesian coordinates, $\mathrm{m} ; \mathrm{p}$ the pressure, $\mathrm{N} / \mathrm{m}^{2} ; \rho$ the fluid density, $\mathrm{kg} / \mathrm{m}^{3} ; \mathrm{u}_{\infty}$ the free stream velocity, $\mathrm{m} / \mathrm{s} ;(\mathrm{u}, \mathrm{v}, \mathrm{w})$ the fluid velocities, $\mathrm{m} / \mathrm{s} ; \mathrm{T}$ the temperature, $\mathrm{K} ; \mathrm{T}_{\mathrm{in}}$ unit cell inlet temperature, $\mathrm{K} ; \mathrm{T}_{\mathrm{w}}$ the tubes surface temperature, $\mathrm{K}$; L the array length in the flow direction, $\mathrm{m} ; v$ the fluid kinematic viscosity, $\mathrm{m}^{2} / \mathrm{s}$ and $\alpha$ the fluid thermal diffusivity, $\mathrm{m}^{2} / \mathrm{s}$.

The solution domain of Fig. 1 is composed by the external fluid and half of the solid fin. The solid-fluid interface is included in the solution domain such that mass, momentum and energy are conserved throughout the domain. Eqs. (1) - (5) model the fluid part of the domain. Only the energy equation needs to be solved in the solid part of the domain, accounting for the actual properties of the solid material. The dimensionless energy equation for the solid fin is written as:

$$
\frac{\partial \theta}{\partial \tau}=\frac{1}{\operatorname{Re}_{2 b}} \frac{2 \mathrm{~b}}{\mathrm{~L}} \frac{\alpha_{\mathrm{s}}}{v}\left[\frac{\partial^{2} \theta}{\partial \mathrm{X}^{2}}+\frac{\partial^{2} \theta}{\partial \mathrm{Y}^{2}}+\frac{\partial^{2} \theta}{\partial \mathrm{Z}^{2}}\right]
$$

where a dimensionless time is defined by $\tau=\frac{\mathrm{t}}{\mathrm{L} / \mathrm{u}_{\infty}}, \mathrm{t}$ is the time, and $\alpha_{\mathrm{s}}$ is the solid fin thermal diffusivity, $\mathrm{m}^{2} / \mathrm{s}$.

$$
\text { For steady-state solutions } \frac{\partial \theta}{\partial \tau} \text { is assumed to be }
$$

zero. The solution to Eqs. (1) - (8) subject to appropriate boundary conditions for the extended domain of Fig. 1 delivers the velocities (fluid) and temperature (fluid and solid) fields.

The objective is to find the optimal geometry, such that the volumetric heat transfer densityis maximized, subject to a volume constraint. The engineering design problem starts by recognizing the finite availability of space, i.e., an available space $\mathrm{L} \times \mathrm{H} \times \mathrm{W}$ as a given volume that is to be filled with a heat exchanger. To maximize the volumetric heat transfer density means that 


\section{CIÊNCIA/SCIENCE}

the overall heat transfer rate between the fluid inside the tubes and the fluid outside the tubes will be maximized.

Next, the optimization study proceeds with the identification of the degrees of freedom (variables) that allow the maximization of the overall heat transfer rate between the tubes and the free stream, Q. Three geometric degrees of freedom in the arrangement are identified in this way, i.e.: (i) the spacing between rows of tubes, $\mathrm{S}$; (ii) the tubes eccentricity, e, and (iii) the fin-to-fin spacing, $\delta$. The behavior of $\mathrm{S}$, e and $\delta$ at the extremes indicate the possibility of maximum $\mathrm{Q}$ in the intervals, $0<\mathrm{S}<\mathrm{S}_{\mathrm{m}}, 0<\mathrm{e}<1$ and $0<\delta<\mathrm{W}$.

A comparison criterion between elliptic and circular arrangements with the same flow obstruction cross-sectional area is adopted, i.e., the circular tube diameter is equal to two times the smaller ellipse semi-axis of the elliptic tube. This criterion was also adopted in previous studies Bordalo and Saboya, (1999), Saboya and Saboya (2001), Rocha et al. (1997), and Matos et al. (2001).

To complete the problem formulation, the following boundary conditions are then specified for the extended three-dimensional computational domain in agreement with Fig. 2:

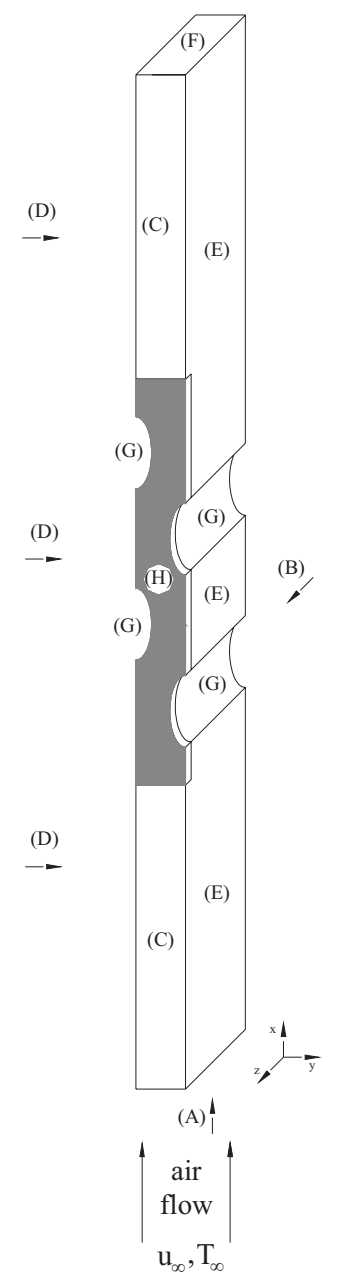

Figure 2. The boundary conditions of the 3-D computational domain.
(A) $\mathrm{U}_{2}=\mathrm{U}_{3}=0 ; \mathrm{U}_{1}=1 ; \theta=0$

(B) and (C) $\mathrm{U}_{3}=0 ; \frac{\partial \mathrm{U}_{1}}{\partial \mathrm{Z}}=\frac{\partial \mathrm{U}_{2}}{\partial \mathrm{Z}}=\frac{\partial \theta}{\partial \mathrm{Z}}=0$

(D) and (E) $\quad \mathrm{U}_{2}=0 ; \frac{\partial \mathrm{U}_{1}}{\partial \mathrm{Y}}=\frac{\partial \mathrm{U}_{3}}{\partial \mathrm{Y}}=\frac{\partial \theta}{\partial \mathrm{Y}}=0$

(F) $\frac{\partial \mathrm{U}_{1}}{\partial \mathrm{X}}=\frac{\partial \mathrm{U}_{2}}{\partial \mathrm{X}}=\frac{\partial \mathrm{U}_{3}}{\partial \mathrm{X}}=\frac{\partial \theta}{\partial \mathrm{X}}=0$

(G) $\mathrm{U}_{1}=\mathrm{U}_{2}=\mathrm{U}_{3}=0 ; \theta=1$

(H) $\mathrm{U}_{1}=\mathrm{U}_{2}=\mathrm{U}_{3}=0 ; \frac{\partial \theta}{\partial \mathrm{Z}}=0$

In order to represent the actual flow with boundary conditions (A) and (F), two extralengths need to be added to the computational domain, upstream and downstream, as shown in Fig. 2. The actual dimensions of these extralengths need to be determined by an iterative numerical procedure, with convergence obtained according to a specified tolerance. Once the geometry of the extended computational domain represented by the unit cell of Fig. 2 is specified, Eqs. (1) - (14) deliver the resulting velocities, pressure and temperature fields in the domain.

The dimensionless overall thermal conductance is described by Matos (2003):

$$
\begin{aligned}
& \widetilde{\mathrm{q}}_{*}=\frac{2}{\mathrm{~N}_{\mathrm{ec}}} \frac{\mathrm{L}}{2 \mathrm{~b}} \frac{\mathrm{H}}{2 \mathrm{~b}} \widetilde{\mathrm{q}} \\
& =\operatorname{Pr} \operatorname{Re}_{\mathrm{L}}\left(\frac{\mathrm{S}}{2 \mathrm{~b}}+1\right)\left(1-\phi_{\mathrm{f}}\right) \bar{\theta}_{\text {out }}
\end{aligned}
$$

where $\phi_{\mathrm{f}}=\frac{\mathrm{n}_{\mathrm{f}} \mathrm{t}_{\mathrm{f}}}{\mathrm{W}}=\frac{\mathrm{t}_{\mathrm{f}}}{\mathrm{t}_{\mathrm{f}}+\delta}$, is the dimensionless fin density in direction $\mathrm{z}\left(0 \leq \mathrm{n}_{\mathrm{f}} \mathrm{t}_{\mathrm{f}} \leq \mathrm{W}\right)$, and $\operatorname{Pr}$ the fluid Prandtl number, $\tilde{v} \alpha$.

The dimensionless mass of solid material was calculated through the following equation:

$$
\begin{aligned}
\widetilde{m}= & \frac{m}{\rho_{s} L^{3}} \\
& =\frac{W}{L^{3}}\left[n_{t} \pi\left(a b\left(a t_{t}\right)\left(b-t_{t}\right)\right)+\phi_{f}\left(L H-n_{t} \pi a b\right)\right]
\end{aligned}
$$

where $t_{t}$ is the thickness of the tube wall and $n_{t}$ is the total number of tubes in the arrangement.

\section{NUMERICAL METHOD}

The numerical solution of Eqs. (1) - (14) was obtained utilizing the finite element method (Zienkiewicz and Taylor, 1989), giving the velocities and temperature fields in the unit cell of Fig. 2.

The implementation of the finite element method for the solution of Eqs. (1) - (5) and (8) starts from obtaining the variational (weak) form of the problem as described by Reddy and Gartling, (1994). The weak form 
is discretized with an 'upwind' scheme proposed by Hughes, (1978), where it is possible to adequate the discrete form of the problem to the physical characteristics of the flow. After developing the discrete form of the problem, the resulting algebraic equations are arranged in matrix form for the steady state three dimensional problem as described by Matos, (2003).

For the 3-D problem of Fig. 1, the computational domain contains both the external fluid and the solid fin. Thus, the solution of Eq. (8) is also required in order to obtain the complete temperature field. Instead of solving separately for the two entities (fluid and solid) and imposing the same heat flux at the interface solid-fluid, as a boundary condition, the solution is sought for the entire domain, simultaneously, with the same set of conservation equations, imposing zero velocities in the solid fin.

\section{EXPERIMENTS}

An experimental rig was built in the laboratory to produce the necessary experimental data to validate the 3D numerical optimization of finned arrangements, and to perform the experimental optimization of finned arrangements. Figure 3 shows a schematic drawing of the experimental apparatus utilized in this study.

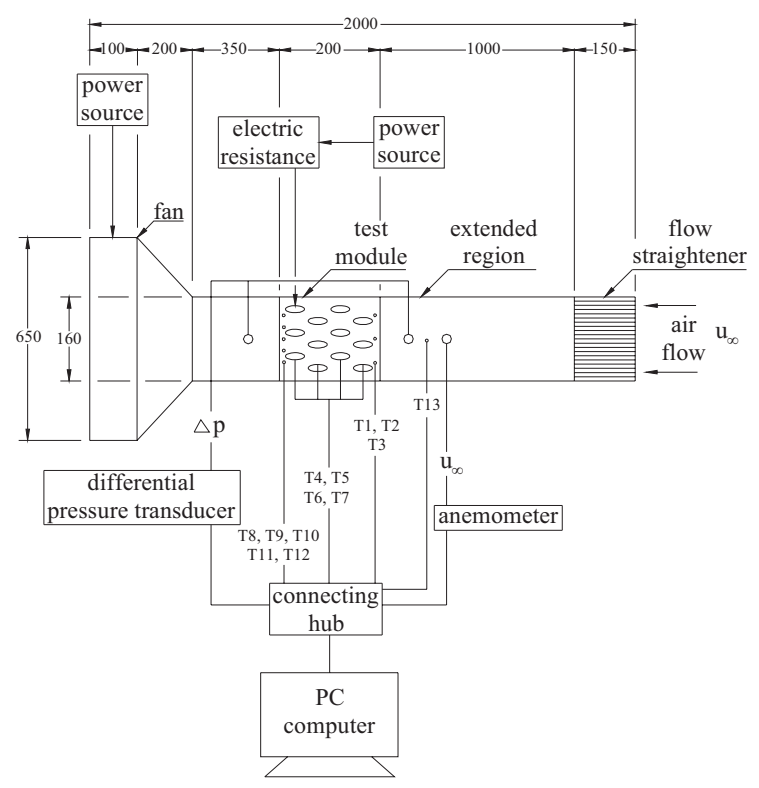

Figure 3. Experimental apparatus.

The circular and elliptic tube arrangements were made from copper circular tubes, all the fins were made from aluminum plates and the electric heaters consisted of double step tubular electric resistances. Twelve high precision thermistors were placed in each test module. All the thermistors were placed in the midplane between the side walls of the wind tunnel and at the midline of the elemental channels. Three thermistors were placed at the arrangement inlet (T1 - T3), five at the outlet (T8 $\mathrm{T} 12)$, and four at the tubes surfaces in one elemental channel (T4 - T7). An additional thermistor (T13) was placed at the midpoint of the extended region to measure the non-disturbed free stream temperature. The velocity measurements were taken with a vane-type digital anemometer and the pressure drop measurements were taken with a pressure transducer, which was connected to a digital pressure meter. The differential pressure measurements had the finality of measuring the pressure drop across each arrangement in all experiments, as shown in Fig. 3. The experimental work involved the acquisition of temperature data in real time.

The objective of the experimental work was to evaluate the volumetric heat transfer density (or overall thermal conductance) of each tested arrangement by computing $\widetilde{\mathrm{q}}_{*}$ with Eq. (15) through direct measurements of $\mathrm{u}_{\infty}\left(\operatorname{Re}_{2 \mathrm{~b}}\right)$, and $\overline{\mathrm{T}}_{\text {out }}, \overline{\mathrm{T}}_{\mathrm{w}}$ and $\mathrm{T}_{\infty}\left(\bar{\theta}_{\text {out }}\right)$. Five runs were conducted for each experiment. Steady-state conditions were reached after 3 hours in all the experiments. The precision limit for each temperature point was computed as two times the standard deviation of the 5 runs (Editorial, 1993). It was verified that the precision limits of all variables involved in the calculation of $\widetilde{q}_{*}$ were negligible in presence of the precision limit of $\bar{\theta}_{\text {out }}$, therefore $\mathrm{P}_{\widetilde{\mathrm{q}}_{*}} \cong \mathrm{P}_{\bar{\theta}_{\text {out }}}$. The thermistors, anemometer, properties, and lengths bias limits were found negligible in comparison with the precision limit of $\widetilde{\mathrm{q}}_{*}$. As a result the uncertainty of $\widetilde{\mathrm{q}}_{*}$ was calculated by:

$$
\frac{\mathrm{U}_{\widetilde{\mathrm{q}}_{*}}}{\widetilde{\mathrm{q}}_{*}}=\left[\left(\frac{\mathrm{P}_{\widetilde{\mathrm{q}}_{*}}}{\widetilde{\mathrm{q}}_{*}}\right)^{2}+\left(\frac{\mathrm{B}_{\widetilde{\mathrm{q}}_{*}}}{\widetilde{\mathrm{q}}_{*}}\right)^{2}\right]^{1 / 2} \cong \frac{\mathrm{P}_{\bar{\theta}_{\text {out }}}}{\bar{\theta}_{\text {out }}}
$$

where $\mathrm{P}_{\bar{\theta}_{\text {out }}}$ is the precision limit of $\bar{\theta}_{\text {out }}$.

The tested arrangements had a total of twelve tubes placed inside the fixed volume LHW, with four tubes in each unit cell (four rows). For a particular tube and plate fin geometry, the tests started with an equilateral triangle configuration, which filled uniformly the fixed volume, with a resulting maximum dimensionless tube-to-tube spacing $\mathrm{S} / 2 \mathrm{~b}=1.5$. The spacing between tubes was then progressively reduced, i.e., $\mathrm{S} / 2 \mathrm{~b}=1.5,0.5,0.25$ and 0.1 , and in this interval an optimal spacing was found such that $\widetilde{\mathrm{q}}_{*}$ was maximum. All the tested arrangements had the aspect ratio $\mathrm{L} / 2 \mathrm{~b}=8.52$.

Two free stream velocities set points were tested, $\mathrm{u}_{\infty}=0.1$ and $0.13 \mathrm{~m} / \mathrm{s}$, corresponding to $\operatorname{Re}_{2 \mathrm{~b}}=100$ and 125, respectively. The largest uncertainty calculated according to Eq. (20) in all tests was $\mathrm{U}_{\widetilde{\mathrm{q}}_{*}} / \widetilde{\mathrm{q}}_{*}=0.048$. 


\section{RESULTS AND DISCUSSION}

The results obtained in this study are divided in two parts: (i) experimental validation of 3-D numerical results for finned arrangements, and (ii) global optimization results with respect to tube-to-tube spacing, eccentricity and fin density.

To obtain accurate numerical results, several mesh-refinement tests were conducted. The monitored quantity was the dimensionless overall thermal conductance, computed with Eq. (15), according to the following criterion:

$\varepsilon=\left|\widetilde{\mathrm{q}}_{*, \mathrm{j}}-\widetilde{\mathrm{q}}_{*, \mathrm{j}-1}\right| /\left|\widetilde{\mathrm{q}}_{*, \mathrm{j}}\right| \leq 0.02$

where $\mathrm{j}$ is the mesh iteration index, i.e., as $\mathrm{j}$ increases the mesh is more refined. When the criterion is satisfied, the $\mathrm{j}-1$ mesh is selected as the converged mesh.

For all cases the mesh was established to consist of 17160 nodes and 13200 elements.

The numerical results obtained with the finite element code are validated by direct comparison to experimental results obtained in the laboratory for circular and elliptic arrangements. According to Fig. 1 the dimensions of the fixed volume for the experimental optimization procedure were $\mathrm{L}=135.33 \mathrm{~mm}, \mathrm{H}=115.09$ $\mathrm{mm}, \mathrm{W}=152 \mathrm{~mm}$, and $\mathrm{D}=2 \mathrm{~b}=15.875 \mathrm{~mm}$. All the arrangements had $\mathrm{N}_{\mathrm{ec}}=6$ and $\mathrm{N}=4$, where $\mathrm{N}$ is the number of tubes in one unit cell.

The numerical and experimental optimization procedures followed the same steps. First, for a given eccentricity, the dimensionless overall thermal conductance, $\widetilde{\mathrm{q}}_{*}$, was computed with Eq. (15), for the range $0.1 \leq \mathrm{S} / 2 \mathrm{~b} \leq 1.5$. The same procedure was repeated for $\mathrm{e}=0.45,0.5,0.6$ and 1 .

The numerical and experimental double optimization results for finned tubes $\left(\phi_{f}=0.006\right)$ with respect to tube-to-tube spacings and eccentricities are shown in Fig. (4), together with the corresponding experimental results, for $\operatorname{Re}_{2 b}=100$ and 125. The direct comparison of $\tilde{\mathrm{q}}_{*, \mathrm{~m}}$ obtained numerically and experimentally shows that the results are in good agreement. The agreement is remarkable if we consider that in the experiments the tested arrays had uniform heat flux, and were not large banks of cylinders. In the numerical simulations the domain was infinitely wider (i.e., no influence from the wind tunnel walls) and with isothermal tubes. An optimal eccentricity was not obtained experimentally, since an arrangement with $\mathrm{e}<0.5$ was not built. However, the numerical results were validated by the good agreement with the experimental results for e $=0.5,0.6$ and 1 . Hence, the numerical results obtained for $\mathrm{e}=0.45$ are also expected to be accurate. At $\mathrm{e}=0.45$, $\widetilde{\mathrm{q}}_{*}, \mathrm{~m}$ drops considerably with respect to $\mathrm{e}=0.5$, determining an optimal pair $(\mathrm{S} / 2 \mathrm{~b}, \mathrm{e})_{\mathrm{opt}}=(0.5,0.5)$ for the twice maximized overall heat transfer $\widetilde{\mathrm{q}}_{*, \mathrm{~mm}}$.

Figure 5 shows an intermediate step in the optimization procedure in order to allow the comparison between the optimal elliptic configuration with the optimal circular one. It is observed that $\widetilde{\mathrm{q}}_{*}, \mathrm{~m}$ for the elliptic arrangement $\quad(\mathrm{e}=0.5)$ optimized with respect to tubeto-tube spacing is higher than $\widetilde{\mathrm{q}}_{*}, \mathrm{~m}$ for the circular arrangement $(\mathrm{e}=1)$ for all fin densities, $\phi_{\mathrm{f}}$. Furthermore, the elliptic configuration requires less fins than the circular one at optimal conditions, i.e., at the optimal pair $(\mathrm{S} / 2 \mathrm{~b}$, $\left.\phi_{\mathrm{f}}\right)_{\mathrm{opt}}$. It is possible to determine the total mass of material in dimensionless terms, through Eq. (16), at $\left(\mathrm{S} / 2 \mathrm{~b}, \phi_{\mathrm{f}}\right)_{\mathrm{opt}}$ for both arrangements. The result of this analysis shows that the total dimensionless mass of the optimal elliptic arrangement is $32 \%$ smaller than the optimal circular one.

Figure 6 shows the results of global optimization with respect to the three degrees of freedom, $S / 2 b$, e and $\phi_{\mathrm{f}}$. An optimal set of geometric parameters was numerically determined such that $\widetilde{\mathrm{q}}_{*}$ was three times maximized, i.e., $\left(\mathrm{S} / 2 \mathrm{~b}, \mathrm{e}, \phi_{\mathrm{f}}\right)_{\mathrm{opt}} \cong(0.5,0.5,0.06)$.

Figure 7 illustrates the temperature distribution of plate fins for four-row heat exchangers for circular and elliptic (e = $0.5)$ tubes, $\mathrm{S} / 2 \mathrm{~b}=0.5$ and with $\operatorname{Re}_{2 \mathrm{~b}}=100$. The effect of the variation of eccentricity is observed comparing cases (a) and (b) in Fig. 7. It is also shown that the elliptical arrangement is more efficient than circular one because the fin temperature distribution is more uniform in the elliptic configuration than in the circular one, and closer to tube wall temperature, characterizing a better thermal contact between the tubes and the fluid in the elliptic arrangement. As stated in section 2, the governing equations are for the laminar regime. Therefore, the results of Figs. 4 - 7 were obtained for low Reynolds numbers, i.e., $\operatorname{Re}_{2 \mathrm{~b}}=100$ and 125. For higher Reynolds numbers, convergence to numerical solutions becomes increasingly more difficult, indicating the flow is reaching a regime of transition to turbulence.

From all numerical and experimental results obtained in this study, it is important to stress that a heat transfer gain of up to $19 \%$ was observed in the optimal elliptic arrangement with $\mathrm{e}=0.5$, as compared to the optimal circular one.

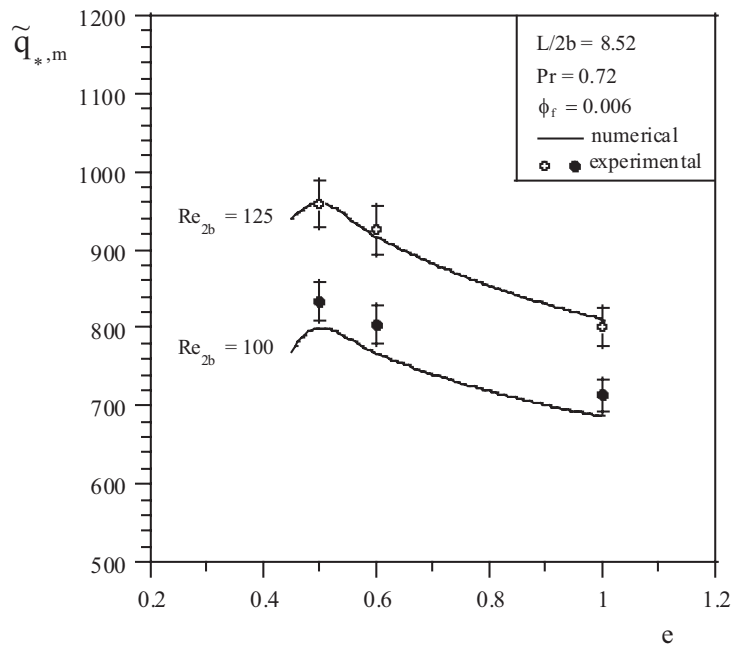

Figure 4. Numerical and experimental optimization results for finned arrangements. 


\section{CIÊNCIA/SCIENCE}

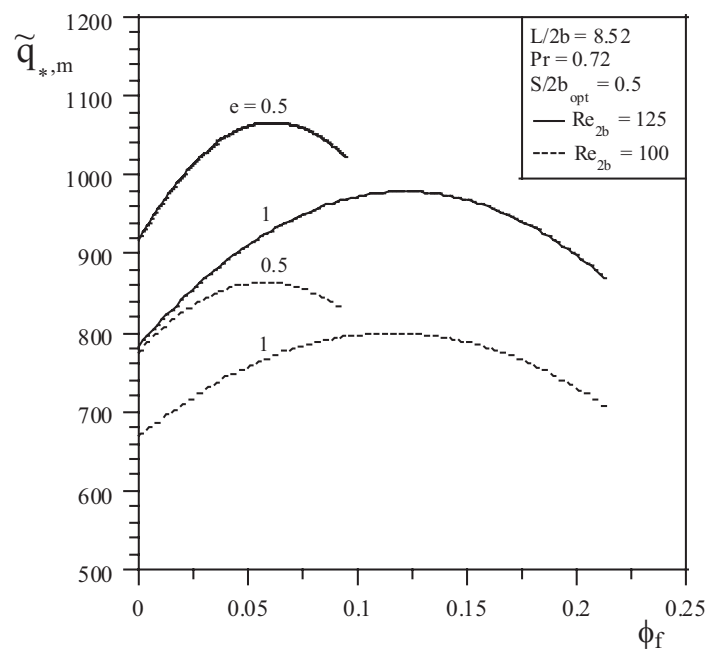

Figure 5. Comparison of the numerical optimization results for finned circular and elliptic arrangements.

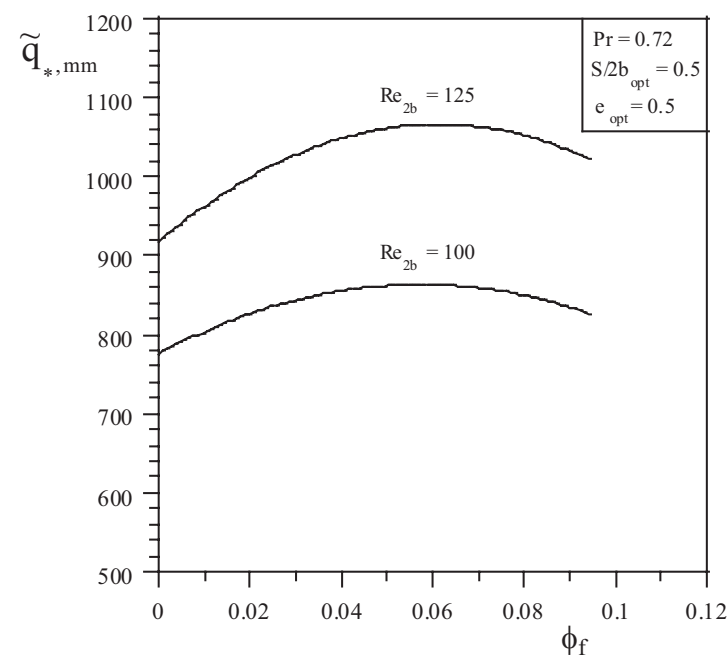

Figure 6. Numerical global optimization results for finned arrangements.
R. S. Matos et al. Optimally Staggered...

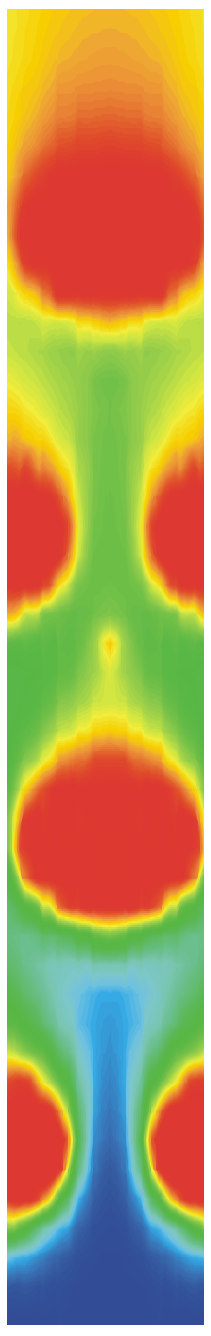

(a)
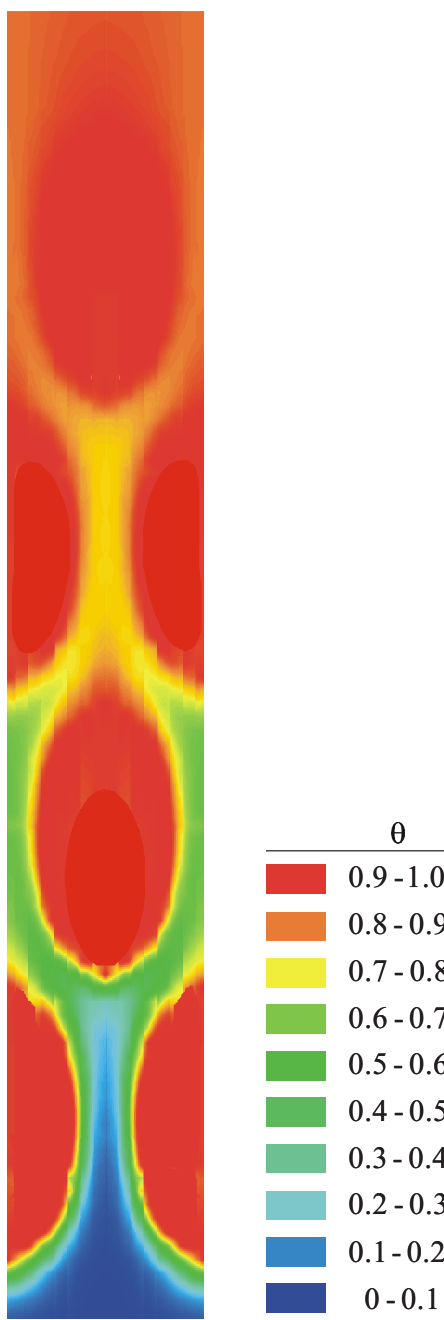

(b)
Figure 7. Fin temperature distribution for four-row tubes and plate fin heat exchangers: (a) $\mathrm{S} / 2 \mathrm{~b}=0.5, \quad \mathrm{e}=1$, $\left(\phi_{\mathrm{f}}=0.006\right)$ and $\mathrm{Re}_{2 \mathrm{~b}}=100 ;$ (b) $\mathrm{S} / 2 \mathrm{~b}=0.5, \quad \mathrm{e}=0.5$, $\left(\phi_{\mathrm{f}}=0.006\right)$ and $\mathrm{Re}_{2 \mathrm{~b}}=100$.

\section{CONCLUSIONS}

In this work, a theoretical, numerical and experimental study was conducted to demonstrate that finned circular and elliptic tubes heat exchangers can be optimized for maximum heat transfer, under a fixed volume constraint. The internal geometric structure of the arrangements was optimized for maximum heat transfer. Better global performance is achieved when flow and heat transfer resistances are minimized together, i.e., when the imperfection is distributed in space optimally (Bejan, 2000). Optimal distribution of imperfection represents flow architecture, or constructal design.

The results were presented nondimensionally to allow for general application to heat exchangers of the type treated in this study. A suitable equivalent pressure drop criterion permitted the comparison between circular and elliptic arrangements on a heat transfer basis in the most isolated way possible. A heat transfer gain of up to $19 \%$ was observed in the optimal elliptic arrangement, as compared to the optimal circular one. The heat transfer gain, combined with the relative total dimensionless 


\section{CIÊNCIA/SCIENCE}

material mass reduction of up to $32 \%$ observed in this study, show the elliptical arrangement has the potential for a considerably better overall performance and lower cost than the traditional circular one.

Three degrees of freedom were investigated in the heat exchanger geometry, i.e., tube-to-tube spacing, eccentricity and fin-to-fin spacing. Global optima were found with respect to tube-to-tube spacing, eccentricity and fin-to-fin spacing, i.e., $\left(\mathrm{S} / 2 \mathrm{~b}, \mathrm{e}, \phi_{\mathrm{f}}\right)_{\mathrm{opt}} \cong(0.5,0.5,0.06)$ for $\operatorname{Re}_{2 b}=100$ and 125. Such globally optimized configurations are expected to be of great importance for actual heat exchangers engineering design, and for the generation of optimal flow structures in general.

\section{NOMENCLATURE}

a larger ellipses semi-axis, $\mathrm{m}$

b smaller ellipses semi-axis, $\mathrm{m}$

$\mathrm{B}_{\mathrm{a}} \quad$ bias limit of quantity a

$\mathrm{c}_{\mathrm{p}} \quad$ fluid specific heat at constant pressure, J/(kg.K)

D tube diameter, $\mathrm{m}$

e ellipses eccentricity, b/a

$\mathrm{H} \quad$ array height, $\mathrm{m}$

$\mathrm{k} \quad$ fluid thermal conductivity, $\mathrm{W} /(\mathrm{m} . \mathrm{K})$

L array length, $m$

$\mathrm{L} / 2 \mathrm{~b} \quad$ array length to smaller ellipses axis aspect ratio

$\mathrm{m} \quad$ total mass of the arrangement, $\mathrm{kg}$

$\widetilde{\mathrm{m}}$ dimensionless total mass of the arrangement

$\mathrm{n}_{\mathrm{f}} \quad$ number of fins

$\mathrm{n}_{\mathrm{t}} \quad$ total number of tubes

$\mathrm{N} \quad$ number of tubes in one unit cell

$\mathrm{N}_{\mathrm{ec}} \quad$ number of elemental channels

p pressure, $\mathrm{N} / \mathrm{m}^{2}$

$\mathrm{P} \quad$ dimensionless pressure

$\mathrm{Pe}_{2 \mathrm{~b}} \quad$ Peclet number based on smaller ellipses axis

Pr fluid Prandtl number, $v / \alpha$

$\mathrm{P}_{\mathrm{a}} \quad$ precision limit of quantity a

$\widetilde{\mathrm{q}}_{*} \quad$ dimensionless overall thermal conductance,

Eq.(15)

Q overall heat transfer rate, $\mathrm{W}$

$\mathrm{Re}_{2 b} \quad$ Reynolds number based on smaller ellipses axis, $\mathrm{u}_{\infty} 2 \mathrm{~b} / \mathrm{v}$

$\mathrm{S} \quad$ spacing between rows of tubes, m, Fig. 1

S/D dimensionless spacing between rows of tubes (circular arrangement)

$\mathrm{S} / 2 \mathrm{~b}$ dimensionless spacing between rows of tubes (elliptic arrangement)

$\mathrm{t}$ time, $\mathrm{s}$

$\mathrm{t}_{\mathrm{f}} \quad$ fin thickness, $\mathrm{m}$

$\mathrm{t}_{\mathrm{t}} \quad$ tube thickness, $\mathrm{m}$

$\mathrm{T}$ temperature, $\mathrm{K}$

$\overline{\mathrm{T}} \quad$ average fluid temperature, $\mathrm{K}$

$\mathrm{u}_{1}, \mathrm{u}_{2}, \mathrm{u}_{3} \quad$ velocity components, $\mathrm{m} / \mathrm{s}$

\section{R. S. Matos et al. Optimally Staggered...}

$\mathrm{U}_{1}, \mathrm{U}_{2}, \mathrm{U}_{3}$ dimensionless velocity components

$\mathrm{U}_{\mathrm{a}} \quad$ uncertainty of quantity a

W array width, $\mathrm{m}$

$\mathrm{x}, \mathrm{y}, \mathrm{z} \quad$ cartesian coordinates, $\mathrm{m}$

$\mathrm{X}, \mathrm{Y}, \mathrm{Z}$ dimensionless cartesian coordinates

\section{Greek symbols}

$\alpha \quad$ thermal diffusivity, $\mathrm{m}^{2} / \mathrm{s}$

$\varepsilon \quad$ mesh convergence criterion, Eq. (21)

$\delta \quad$ fin-to-fin spacing, $m$

$\theta \quad$ dimensionless temperature

$\bar{\theta} \quad$ dimensionless average fluid temperature

$v \quad$ fluid kinematic viscosity, $\mathrm{m}^{2} / \mathrm{s}$

$\rho$ density, $\mathrm{kg} / \mathrm{m}^{3}$

$\phi_{\mathrm{f}} \quad$ dimensionless fin density in direction $\mathrm{z}$

$\tau \quad$ dimensionless time

\section{Subscripts}

$\begin{array}{ll}\text { in } & \text { unit cell inlet } \\ \mathrm{m} & \text { maximum } \\ \text { opt } & \text { optimal } \\ \text { out } & \text { unit cell outlet } \\ \text { s } & \text { solid tube wall and fin material } \\ \text { w } & \text { tube surface } \\ \infty & \text { free stream }\end{array}$

\section{ACKNOWLEDGEMENTS}

The authors acknowledge with gratitude the support of the Program of Human Resources for the Oil Sector and Natural Gas, of the Brazilian Oil National Agency - PRH-ANP/MCT. 


\section{REFERENCES}

Bejan, A., 1995, “Convection Heat Transfer", 2nd Edition, Wiley, New York, (Chapters 2-3).

Bejan, A., 2000, "Shape and Structure, from Engineering to Nature", Cambridge University Press, Cambridge, UK.

Bordalo, S. N., and Saboya, F. E. M., 1999, "Pressure drop coefficients for elliptic and circular sections in one, two and three-row arrangements of plate fin and tube heat exchangers", J. Braz. Soc. Mech. Sci. XXI (4), pp. 600-610.

Editorial, 1993, "Journal of heat transfer policy on reporting uncertainties in experimental measurements and results", ASME Journal of Heat Transfer 115, pp. 5-6.

Fowler, A. J., and Bejan, A., 1994, "Forced convection in banks of inclined cylinders at low Reynolds numbers", Int. J. Heat Fluid Flow, 15, pp. 90-99.

Hughes, T. J. R., 1978, "A simple scheme for developing upwind finite elements", Int. J. Numer. Meth. in Eng. 12, pp. 1359-1365.

Matos, R. S., Vargas, J. V. C., Laursen, T. A., and Saboya, F. E. M., 2001, "Optimization study and heat transfer comparison of staggered circular and elliptic tubes in forced convection", Int. J. Heat Mass Transfer 20, pp. 3953-3961.

Matos, R. S., 2003, “Otimização e Comparação de Desempenho de Trocadores de Calor de Tubos Circulares e Elípticos Aletados", Tese de Doutorado, PIPE-UFPR, Curitiba.

Reddy, J. N., and Gartling, D. K., 1994, "The Finite Element Method in Heat Transfer and Fluid Dynamics", CRC Press, Boca Raton, FL, (Chapters 4-5).

Rocha, L. A. O., Saboya, F. E. M. Vargas and J .V. C., 1997, "A comparative study of elliptical and circular sections in one and two-row tubes and plate fin heat exchangers", Int. J. Heat Fluid Flow 18, pp. 247-252.

Saboya, S. M., and Saboya, F. E .M., 2001, "Experiments on elliptic sections in one and two-row arrangements of plate fin and tube heat exchangers", Experimental Thermal and Fluid Science 24, pp. 67-75.

Zienkiewicz, O. C., and Taylor, R. L., 1989, "The Finite Element Method", vol. 1, McGraw-Hill, London, (Chapter 15). 